\title{
EMBEDDING AFFORDABILITY ASSESSMENT IN THE ANALYSIS OF ALTERNATIVES IN DEFENSE MODERNIZATION PROJECTS
}

\author{
Venelin GEORGIEV
}

\begin{abstract}
The significant amount of financial resources, spent on modernizing the armed forces, the importance of acquired defense capabilities for implementation of defense missions and tasks, the limited amount of money for investments in defense are among the arguments supporting the implementation of effective and efficient methods for economic analysis in assessing acquisition projects. The application of new methods for economic analysis is a part of the process of innovation intended to give competitive advantages to strategic management in defense. The Economic Evaluation of Alternatives (EEoA) is a tool of defense resource management that focuses on the operational effectiveness and life cycle cost of alternatives within a set of scenarios representing budget limitations. The application of EEoA allows experts and decision-makers to create appropriate structures of any analysis of alternatives for acquisition projects in defense in a way that guarantees the achievement of desired goals.
\end{abstract}

Keywords: Economic Evaluation of Alternatives, EEoA, financial scenarios, defense capabilities, defense resource program management, defense acquisition, operational effectiveness, life cycle cost.

\section{Introduction}

A characteristic common feature of economic resources, including financial capital, is their scarcity that determines the need to seek maximum utility and return in their management. On the other hand is the well known and generally accepted idea of unlimited amounts of human needs which, among other things, have a tendency to reproduce at a higher level when they reach a certain degree of saturation or satisfaction. Summed effects of both economic and social phenomena necessitate choice and making rational, informed and effective decisions to meet existing needs with available resources and in a way that maximizes the utility of the resources used. Defining, motivating, and supporting such decisions is a complex process, the implementation of which would be impossible without the existence, development and application of 
appropriate tools - quantitative and qualitative analytical methods and models for evaluating the effectiveness of the use of resources to meet the needs of people and society.

This dilemma accompanies the management of financial resources in the defense sector. The amount of financial resources is limited by various factors, such as the size of gross domestic product, the state of the economy as a whole, the amount of funds allocated from the state budget in the interest of building and maintaining defense capabilities, the allocation of earmarked funds for security in areas which include personnel, maintenance, training, participation in operations, investments, etc. The limited scope and significant amounts of financial resources for security, on the one hand, and the need for security — one of the existential needs of people - on the other, demand adequate resource decisions and tools to justify and support the implementation of these decisions.

\section{Main thesis and arguments}

The technology to manage defense resources is rather sophisticated and complex; it involves various management systems and requires making common and reasonable management decisions. The effectiveness of spending is measured by the resulting product, namely the security of society, guaranteed on the basis of established and maintained defensive abilities obtained as a product of rational program management of defense resources and innovative and technologically correctly oriented defense procurement. Guarantees for achieving the desired efficiency and effectiveness of management decisions related to resources are the sought in the objective, scientifically sound and generally accepted methods and models applied in practice by competent experts, managers and politicians.

Resource decisions are made within a process, that in itself needs to be transparent to decision makers, e.g., to allow the preservation of a clear audit trail from national security objectives, through defense objectives to taxpayers' money. ${ }^{1}$ Among the various requirements towards the resource management the most important are:

- How to create affordable, i.e. resource constraint plans?

- How to deal with uncertainty?

- How to support the senior civilian leadership of a defense ministry in the exercise of its authority and obligations as agents of democratic control of the armed forces?

Often, decisions of required capabilities, or defense requirements in general, are resource informed, i.e., generally assessed as realistic, but not necessarily resource constrained, i.e., fitting within defense budget forecasts. But when program decisions are 
made, the cost of the defense program for each future year does not exceed the defense budget forecast for the respective year. ${ }^{2}$

To summarize these arguments, the degree of coherence and integration between management systems and processes related to management of financial resources for defense does not provide for effective management. As a result, there are significant risks and problems in trying to achieve the maximum effect and maximal utility. Additional analytical instruments - methods, models, and other decision support toolsare needed in order to overcome existing deficiencies.

This thesis may be supported by many arguments and examples. For example, the U.S. Government Office for defense procurement concludes that the processes for determining required capabilities, for planning, programming and budgeting (PPBS), and for developing, manufacturing, and acquisition of defense products are not sufficiently integrated, which leads to more defense investment programs and projects than can be funded from the defense budget. ${ }^{3}$ Another consequence of the lack of sufficient coordination between systems and processes is the adoption of investment programs and projects in defense without having sufficiently comprehensive, detailed and reliable estimates of costs and associated resources. In a study conducted in 2009, the Business Executives for National Security (BENS) concludes that most of the requirements for defense capabilities are determined in the absence of adequate input as to the suitability of the investment programs and projects in terms of budgetary constraints. ${ }^{4}$ To continue with examples from the U.S., the Pentagon has announced plans to invest 375 billion dollars in development, manufacturing or purchasing weapons systems over the next five or six years, while operating and maintaining existing systems will require additional billions of dollars. ${ }^{5}$ The 2008 assessment of the investment portfolio of U.S. defense grew by 285 billion dollars over the previous 2007.

But what are the results of the implementation of expensive projects to modernize the Armed Forces? In most cases investment projects do not yield the intended effects in terms of defense capabilities, making it necessary to spend additional resources to extend existing or start new acquisition projects. On the other hand, the increase of unforeseen costs of investment projects already reduces the possibilities of funding new ones. Another related shortcoming is the fact that the delayed implementation of investment projects leads to a delay in the expected delivery of defense capabilities needed by the Armed Forces to fulfill their security missions and operations. Eloquent proof of the quality and effectiveness of project management in the defense, and particularly the methods of economic analysis, are the results of analysis of the investment portfolio of U.S. Defense in $2007,{ }^{6}$ according to which:

- The total number of implemented investment programs is 95 ; 
- The cost of research and development programs have increased unexpectedly by 40 percent;

- The total costs of investment programs has increased by 26 percent;

- The absolute value of the total contingency programs is 295 billion dollars;

- The number of programs with more than 25 percent unexpected increase in the total cost represents 44 percent of all investment programs;

- The average delay in implementation of investment programs is 21 months.

In sum, there is obviously an imbalance between the huge investment costs for modernizing the armed forces and the quality and effectiveness of the scientific instruments (methods and models) for the management of acquisition projects with emphasis on their evaluation and selection for funding.

Other examples are provided by the recent experience of Bulgaria, where the 2010 defense budget was reduced significantly both in absolute terms and as a percentage of the Gross Domestic Product (GDP). That resulted in a budget distribution leaving only seven million BGN for capital expenditures, or 0.8 percent of the defense budget in 2010, compared to an average of 20-22 percent in previous years. The sharp reduction in the amount of the investment costs in the defense budget, among other things, increased the demands on the process of reasoning and decision making to financial management over the quality of project management and in particular to the application of rational methods of economic analysis in the selection and evaluation of force modernization projects.

Focusing on national practices in implementing defense resource management systems, it can be said that Bulgaria faces similar problems to the one presented above. For example, within one planning cycle, cost estimates of the country's commitments to the NATO defense and security in the form of force goals increased several times from the moment commitments were made to the actual assessment of costs in the programming and budgeting cycle, and the latter in turn have been tens of percentages lower that the value of real investment (acquisition) transactions. The adverse effects from implementing such a mechanism to evaluate, plan and implement defense investment programs and projects can be classified in several ways.

First, attempts to reduce investment costs often lead to the development of incomplete and therefore poor investment projects. In the language of project management, too often the scope of the investment project does not match the scope of the defense products, which is the subject of investment. Here it is sufficient to mention examples of acquisition of ships for BG Navy needs without appropriate units to provide power while on base, or purchase of training aircraft without including within the scope of the investment project of a computer class to support the initial training of pilots. As a 
result of such irrational investment decisions, the cost of the life cycle of defense products increases and/or it becomes necessary to launch new investment projects for the acquisition of additional equipment. Ultimately, all that leads to defense resource management of lower quality and impedes the implementation of capability targets.

Second, the desire of each program manager to run their own investment projects is often a reason for reducing the estimates of investment costs by lowering the values of cost factors, ignoring certain costs of the life cycle of defense products, etc. Thus, they attempt to run more investment projects than can realistically be financed from the defense budget. As a consequence, in the implementation phase financial resources have to be transferred from an investment project to another and from one major program to another, and that inevitably affects the quality of performance. Often it is necessary to reduce the scope, to suspend or withdraw a number of investment projects. Recent projects for the acquisition of transport aircraft and helicopters for the Air Force and automotive equipment for the Land Forces may turn into textbook cases in that respect. Final result of such ineffective management of defense resources is the delay in providing required defense capabilities, which often is accompanied by a reduction in the level and quality of these capabilities.

The issue of reporting the eligibility of investment projects in terms of defense spending is becoming of extreme importance. The 2010 White Paper on Defense and Armed Forces of Bulgaria declares the intention of the leadership of the Ministry of Defense (MoD) to develop a long-term investment plan incorporating all force modernization projects aimed at building and maintaining the required defense capabilities. In an attempt to provide financial eligibility and launch certain acquisition projects, the MoD intends to include in the plan investment projects that are "financially feasible in the period until 2020."7 Rational management decisions would require financial feasibility of modernization projects throughout their life cycle in order to include them in the investment plan and, respectively, a loner horizon of investment planning is necessary. The designers of this plan should take account of risks related to financing opportunities, depreciation of financial capital in time, economic viability, the dynamics of innovation and technology, possible changes in the security environment, and the commitments of the country to international security, etc.

The development and implementation of improved or new methods of economic analysis in the evaluation and selection of investment projects to modernize the Armed Forces can be considered part of the innovation process in defense. Accepting that innovation is a "new idea that works," opportunities to utilize available methods of economic analysis to resolve analytically challenging tasks in defense resource management or to approach existing analytical tasks in new, more effective ways. No matter whether innovation is of the "push" type, implementing ideas coming from science and research, or "pulled" from needs 
identified in practice, if it helps achieve the objectives of security and defense and ensures maximization of utility for individuals and society. The implementation of innovative ideas undoubtedly increases the competitiveness of the defense sector in the allocation of public resources among areas such as health, education, internal order, etc. The Economic Evaluation of Alternatives (EEoA) ${ }^{9}$ is an example of such innovative method for performing economic analysis in evaluating and selecting investment projects to modernize the Armed Forces, utilizing a number of scenarios for financing from the defense budget.

One of the major differences between traditional methods of analysis of alternatives (AoA) and EEoA is the content of the reported input variables in the analysis (Figure 1). While examining operational efficiency and cost of the life cycle of defense products like AoA, EEoA adds a new variable - uncertainty of existing and projected financial constraints. Uncertainty is represented by possible scenarios for funding, thus treating the issue of affordability of the alternatives under examination. One possible implementation is to incorporate in the analysis funding scenarios for 'optimistic,' 'pessimistic' and 'most likely' funding option.

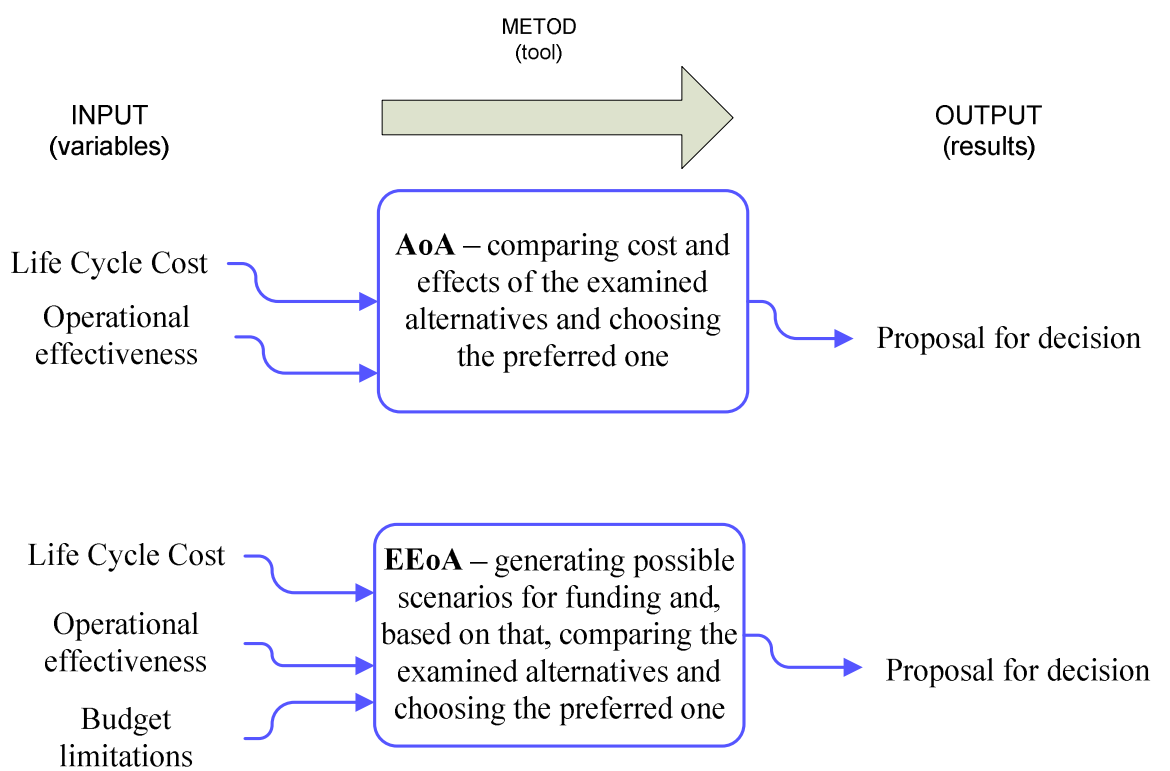

Figure 1: Variables used in AoA and EEoA. 


\section{Description of the Current Situation}

Nowadays, the analysis of alternatives as a practical tool for decision support is applied in the capabilities-oriented force planning process to determine the structure of the armed forces, to analyze and select options for action related to the size defense spending, risk management, etc. In this type of analysis the focus is on life-cycle cost and operational effectiveness of alternatives without paying explicit attention to whether alternatives are affordable, i.e. acceptable in terms of anticipated budgetary constraints. The analysis of alternatives seeks to assess costs and effectiveness of competing alternatives; to what extent they are eligible in terms of financial constraints is considered as a separate issue and thus remains in the background. Modeling results are presented as possible decision points in a coordinate system with cost and effects as axes.

In assessing defense investment options, "costs" and "effects" can not be easily combined into an integrated criterion by which to assess and rank investigated alternatives and decide on choosing one of the alternatives. Using criteria to evaluate the effectiveness (Measures of Effectiveness, or MoE) and the cost of the life cycle of alternatives does not solve the problem of combining these two individual estimates. The criteria for assessing performance (Measures of Performance, or MoP) in turn are usually quantitative, systemic in nature, and used among a number of criteria to assess effectiveness. According to Hitch and McKean, ${ }^{10}$ a criterion is a test by which to select an alternative to other, competing with it. Choosing the appropriate criterion is a central problem in defining and implementing the cost-effectiveness analysis. The two most popular criteria used in making decisions based on the AoA include:

- Benefit/cost ratio;

- Determining the weighting of costs and effects.

The use of both criteria is associated with certain problems. The first criterion is being implemented smoothly if there is a scenario that sets budgetary constraints or the level of desired effects. Benefit/cost or effects/costs ratios are used in AoA when neither costs nor benefits/effects of the compared alternatives can be fixed and leveled. Figure 2 presents two alternatives A and B; the realization of each would bring different effects and has a different cost. Alternative $\mathrm{B}$ has a higher value of the effects to alternative A, which is valid with respect to estimates of the costs. The cost/effects is selected as a criterion for comparing the two alternatives:

$$
\frac{\text { Effects } A}{\operatorname{Cost} A}>\frac{\text { Effects } B}{\operatorname{Cost} B}
$$




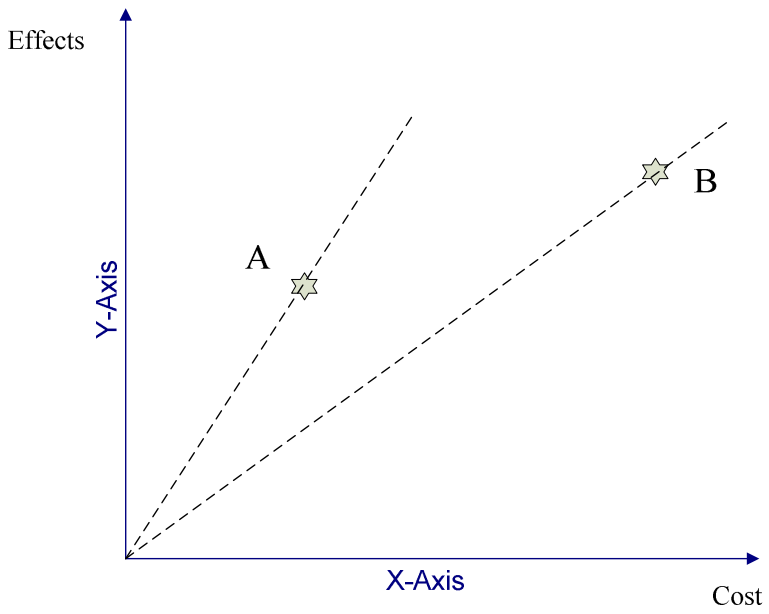

Figure 2: Determining cost/effect ratio for alternatives.

The questions whether actually alternative $\mathrm{A}$ is better than alternative $\mathrm{B}$ and whether it is affordable remain open. Table 1 provides an example of evaluating the effects and costs of both alternatives. Based on data from Table 1, the effect/cost ratio of the two alternatives equals respectively 1 and 0.9 , hence $\mathrm{A}$ is the preferred alternative. In another example, shown in Table 2, the effect/cost ratio for alternative $\mathrm{A}$ is 1 and for alternative $\mathrm{B}-1.1$; hence $\mathrm{B}$ is the preferred alternative.

Table 1. Cost and Effects Data - Example 1.

\begin{tabular}{ccc}
\hline Alternatives & $\begin{array}{c}\text { Cost estimates } \\
\text { In millions of Euro }\end{array}$ & $\begin{array}{c}\text { Effect estimates } \\
\text { In utility }\end{array}$ \\
\hline A & 10 & 10 \\
B & 1000 & 900 \\
\hline
\end{tabular}

Table 2. Cost and Effects Data - Example 2.

Alternatives

A

$\mathrm{B}$

\section{Cost estimates}

In millions of Euro
Effect estimates

In utility
10

1100 
However, comparing the absolute cost of the two alternatives, B is hundred times more expensive than alternative $\mathrm{A}$, which raises the question whether it is possible to finance the more expensive alternative within the existing budgetary constraints. It is obviously necessary to perform analysis and assessment of the utility of getting additional 1090 units from the effects of alternative B for 990 million or to select the lower cost alternative - in this case alternative A.

When using the effects/cost ratio it is recommended to gradually narrow the constraints of comparing alternatives in terms of costs or effects in order to reach the same order of costs or effects and only then choose the preferred alternative. An example of applying a similar approach could include the choice of several home evaluations for the budget available. If during the analysis it is found that the same alternative is preferred in all dimensions of the budget, then obviously it can be accepted as the preferred overall with high degree of confidence. In the event that none of the studied alternatives is best for all measured budget estimates, that is also useful information for decision makers.

The second criterion used in the AoA is associated with determining the weighting of effects and costs. In response to the observed lack of capabilities (capability gap), defined on the basis of scenario planning in response to a threat, planners define requirements towards weapons systems, doctrine, training, readiness levels, etc., so that this gap is overcome. Based on these requirements, we determine criteria for assessing effectiveness, most often constructed as a hierarchical structure in a manner shown in Figure 3.

LEVEL 1

LEVEL 2
LEVEL 3

LEVEL 4 Speed

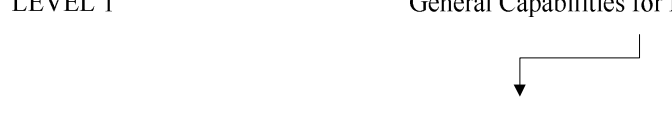

LEV 2

(S)
Capabilities for Airlift
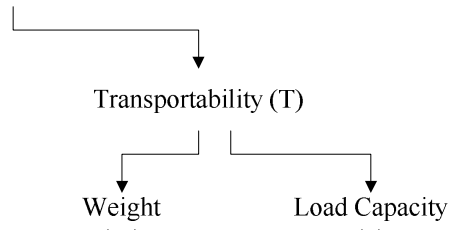

(W)
(P)

Figure 3: Model of hierarchical structure of criteria for evaluating the effects of the studied alternatives. 
The characteristics of the lowest, fourth, level — speed, range, weight, load capacitycan be measured and defined quantitatively. Using the designations in the example on Figure 3, the utility function can be written as: ${ }^{11}$

$$
U=U[M(S, R), T(P, R)]
$$

Using the utility function, the task is to determine the alternative that gives maximum impact per unit cost of resources.

More widely used, similar but more elementary approach to the analysis of alternatives is to determine the weighting of the costs and effects of the studied alternatives and replace them by a function of the utility. For example, the European Union has approved a legislative package to simplify and modernize laws on public procurement used by member states. The package retains the two criteria for evaluating and comparing alternatives - the lowest cost and highest economic value. EU member states are required to publish the values of the weights for each of the criteria applied in determining the highest economic value.

Using the weights $\mathrm{w}_{1}$ and $\mathrm{w}_{2}$, and based on assessments of effects and costs, the value of the utility function for each of the studied alternatives is defined as:

$$
V=w_{1} \text {.Effects }-w_{2} \cdot \text { Cost }
$$

The preferred alternative is the one with the highest value of the utility function.

$$
V=(\text { Effects }, \text { Cost })=\max
$$

The application of this approach involves two major problems: modeling the effects and costs of alternatives and determining the weights. The answer to the second problem depends on the perceived importance of effects and costs in the specific case. For example, if the analysis supports the selection of a water purification plant, we need to decide what is more important: minimizing the cost or maximizing the degree of purification, and their respective proportion.

Using the example shown in Figure 4, depending on the values of the two weightsw and $\mathrm{w}_{2}$, two extreme cases are possible:

- When the effects were evaluated as significantly more important than cost, i.e. $\mathrm{w}_{1} \gg \mathrm{w}_{2}$, B will be the preferred alternative;

- Where costs are assessed as significantly more important than the effects, i.e. $\mathrm{w}_{1}<<\mathrm{w}_{2}$, the preferred alternative will be $\mathrm{A}$.

Extreme cases aside, the question is how to set the values of the two weights $\mathrm{w}_{1}$ and $\mathrm{w}_{2}$. If the affordability of the alternatives is not an issue, i.e. if the budget is considered unconstraint, it can be assumed that $\mathrm{w}_{2}=0$, i.e. alternatives are compared only in terms of their effects. 


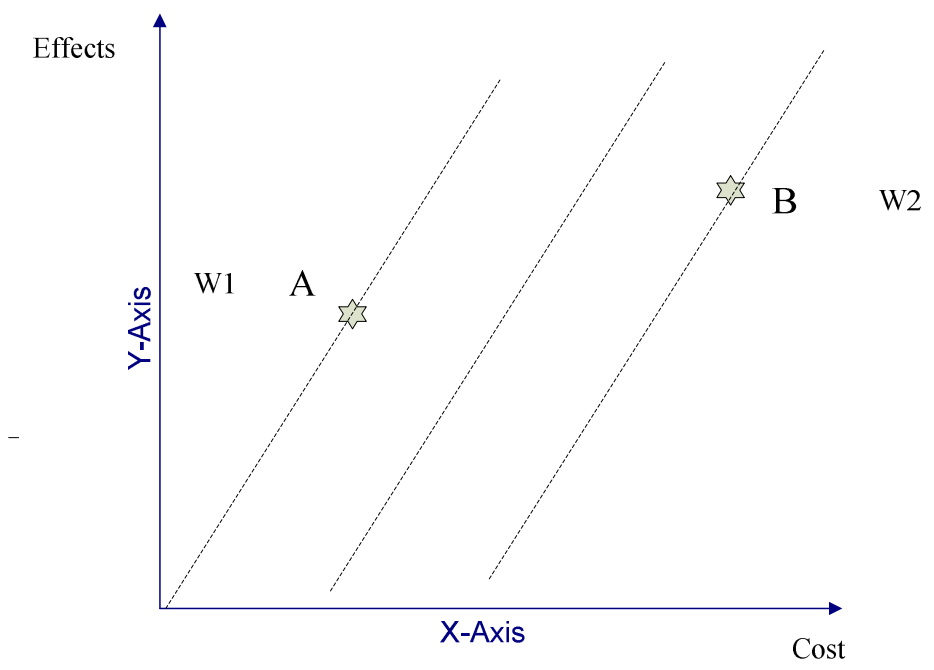

Figure 4: Select an alternative depending on the weight coefficients.

To determine the appropriate weighting factors we need to be aware of resource, e.g. budget constraints. In high degrees of uncertainty analysts tend to underestimate costs, i.e. too lower optimistically their assessments of the necessary resources. As a result, there is a disturbing lack of balance between resources to implement the portfolio of defense programs/projects and the funds committed to that purpose. The probability of success is reduces and risk increases up to the point of failure in building the required defense capabilities in their quantitative, qualitative and temporal aspects.

\section{Embedding affordability assessment into AoA}

One of the main challenges facing strategic management of defense is to achieve a balanced combination (portfolio) of acquisition projects that, among other requirements, are eligible in terms of budgetary constraints. It is possible to address this challenge by enhancing the pool of effective methods of analysis, definition and maintenance of managerial decisions related to defense resource management, as is the method EEoA. This method clearly distinguishes three variables: life cycle cost or Total Ownership Cost (TOC), operational effects, and availability of resources (represented through financial scenarios).

One of the ideas behind EEoA is to improve networking and coordination between the processes of capabilities-based force planning, programmatic defense resources management and defense acquisition. Another innovative idea of EEoA is to use dif- 
ferent budget scenarios to reflect forecasts for the future six-year programming period. Thus, the analysis includes an explicit optimization approach for making acquisition decisions within resource constraints. This approach parallels the optimization approach of PPBS, manifested in search of an optimal set of forces, equipment and maintenance, which maximizes the product 'national security' within budgetary constraints.

In general there are six ways to structure the analysis of EEoA, presented by the model in Figure $5 .^{12}$ More detailed examination of the six options for structuring EEoA allows identifying the following aggregate characteristics:

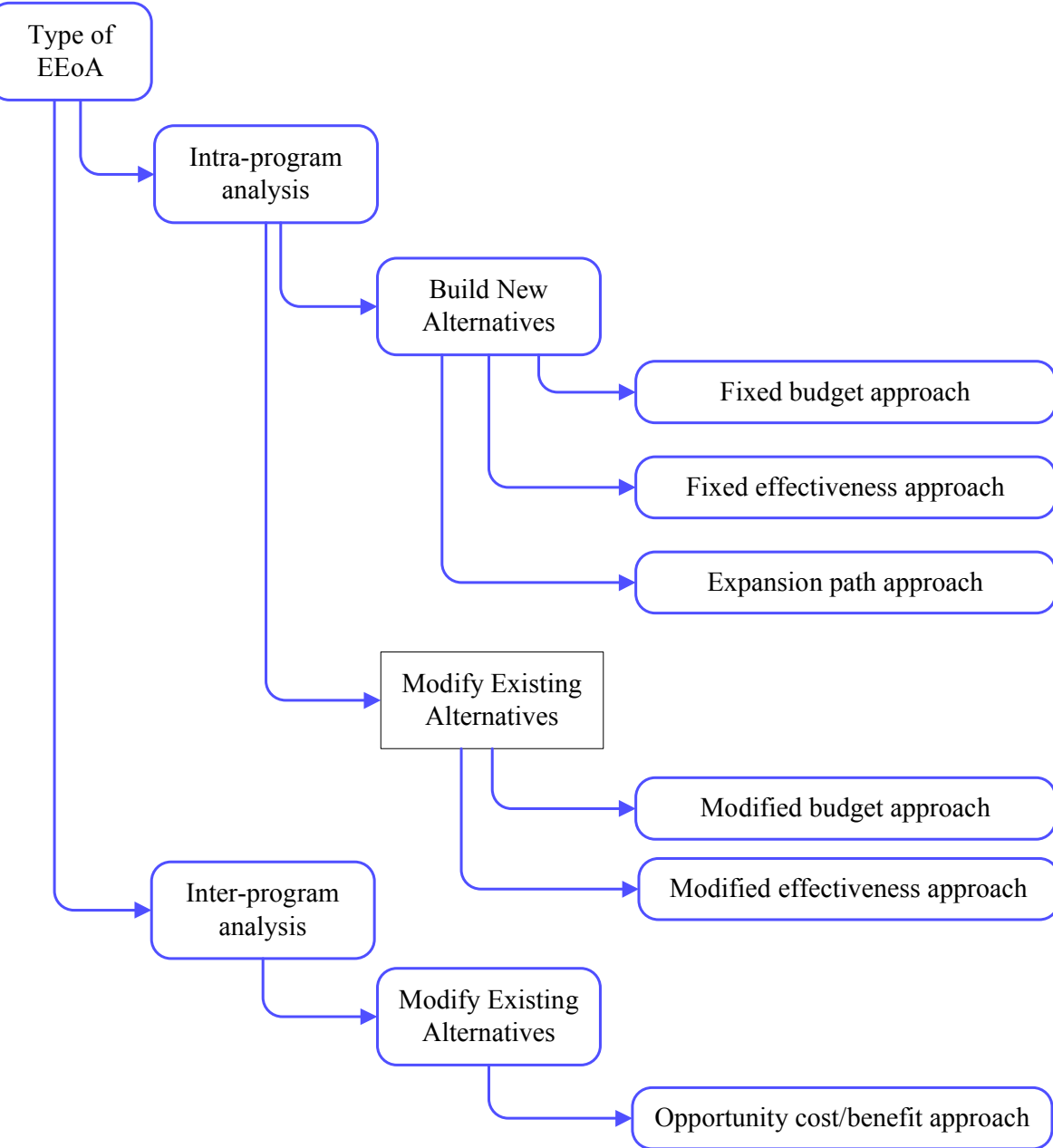

Figure 5: Model of possible cases to structure the analysis of the type EEoA. 
- In the first five approaches costs and effects of a program or projects is analyzed regardless of other programs/projects from the portfolio of the defense organization. In the sixth approach, the analysis the costs and effects take account of all programs/projects included in the portfolio.

- In the first three approaches alternatives are created by the analysts (endogenous alternatives); an example would be comparing alternatives of defense programs generated by experts and the programming team. The last approach allows to compare already established alternatives (exogenous alternatives), for example in assessing the bids of participants in the process of selecting a contractor, e.g. different companies producing multipurpose aircraft participating in the contest for selection of a supplier of such aircraft for the needs of the Bulgarian Air Force.

On the basis of individual characteristics of each of the options (ways) for structuring the EEoA, and considering the advantages they provide, Prof. Francois Melese has developed a decision map, ${ }^{13}$ which significantly eases the practical work of analysts in choosing the preferred option of EEoA depending on the specifics of acquisition project. This map can serve as a guide for analysts and decision makers; it facilitates the analytical process and at the same time puts it on a robust and scientifically sound basis.

\section{Conclusion}

In conclusion we can summarize that the application of EEoA approach to reasoning, support and decision making in the defense acquisition provides several significant advantages. First EEoA made clearer and better understood the problems and challenges which can not find a solution with the broad practical applied AoA approach. Multi-criteria approach to decision making, which is a basis for AoA, focus on life cycle costs and operational efficiency while leaving the affordability of the analyzed project alternatives on a second plan. Next EEoA approach creates conditions for expanding the range of measured variables during the analysis by including financial constraints and financial eligibility of the analyzed alternatives. In practice, this opportunity is realized through the development and implementation financial scenarios for the acquisition project. Do not underestimate the practical application of EEoA approach with the possibility of differential application depending on the characteristics of the acquisition project, practical expression of which is the developed decision map. 


\section{Notes:}

1 Todor Tagarev, "Introduction to Program-based Force Development," in Hari BucurMarcu, Philipp Fluri, and Todor Tagarev, eds., Defence Management: An Introduction (Geneva, DCAF, 2009), pp. 75-92.

2 Tagarev, "Introduction to Program-based Force Development." For further information the reader may refer to Todor Tagarev, "Introduction to Program-based Defense Resource Management," Connections: The Quarterly Journal 5:1 (Spring-Summer 2006): 55-69, $<$ www.pfpconsortium.org/file/introduction-to-program-based-defense-resourcemanagement-by-todor-tagarev $>$.

3 Michael J. Sullivan, Defense Acquisitions: DoD Must Prioritize its Weapon System Acquisitions and Balance Them with Available Resources, Testimony, before the Committee on the Budget, House of Representatives, GAO-09-501T (Washington, D.C.: US Government Accountability Office, March 2009).

4 Sullivan, Defense Acquisitions: DoD Must Prioritize its Weapon System Acquisitions.

5 Sullivan, Defense Acquisitions: DoD Must Prioritize its Weapon System Acquisitions.

6 Sullivan, Defense Acquisitions: DoD Must Prioritize its Weapon System Acquisitions.

7 White Paper on Defence and Bulgarian Armed Forces (Sofia: Ministry of Defense, 2010).

8 Tzvetan Tzvetkov, Innovations and Investments in Defense (Sofia: Stopanstvo, 2004).

9 Francois Melese, Economic Evaluation of Alternatives, Working paper (Monterey, CA: Defense Resources Management Institute, Naval Postgraduate School, 2009).

10 Charles J. Hitch and Roland N. McKean, The Economics of Defense in the Nuclear Age (Cambridge, MA: Harvard University Press, 1967).

11 Dimitar Dimitrov, Economic Analysis "Cost/Benefit" in Defense and Security (Sofia: Stopanstvo, 2010).

12 Melese, Economic Evaluation of Alternatives.

13 Melese, Economic Evaluation of Alternatives.

VENELIN GEORGIEV is associate professor at the Centre for Security and Defense Management in the Institute of Information and Communication Technologies at the Bulgarian Academy of Sciences. He graduated from the Bulgarian Air Force Academy in 1987 and received a PhD degree in management from "G.S. Rakovski” Defense and Staff College. His research interests include defense resource management, defense acquisition and risk management, innovation and investment management, controlling, and economic analysis. E-mail: georgiev@defencemanagement.org. 